\title{
EL MODELO TERRITORIAL DE LA ESPAÑA AUTONÓMICA. RECAPITULACIÓN Y PERSPECTIVAS
}

\author{
José Ma Serrano Martínez \\ Dpto. de Geografía Física, Humana y Análisis Regional \\ Universidad de Murcia
}

\begin{abstract}
RESUMEN
La distribución irregular de la población en las regiones españolas continúa aumentando. Ha seguido concentrándose, con fuerte dinamismo, en las regiones costeras, en especial las mediterráneas, las islas Baleares y Canarias; además de Madrid, región urbana. Frente a ello el gran espacio interior mantiene sus densidades bajas. El conjunto de la economía española ha crecido con fuerza. No ha sido igual en todas las regiones, pero ha permitido una ligera tendencia hacia la convergencia regional, en valores relativos, a pesar de las notables diferencias territoriales. No obstante, aún son numerosas las que registran un nivel medio de riqueza inferior al promedio de la Unión Europea. La descentralización autonómica ha sido rápida y profunda. Se ha conseguido una situación semejante a la de los Estados Federales. Cara al futuro se observa una dinámica dual: frente a cierta ideología política centrífuga, cada vez el funcionamiento de la economía se sustenta en un mercado más integrado, con mejor accesibilidad territorial y mayor cohesión. Entiendo que un devenir de unidad territorial española (espacio periférico dentro de la Unión Europea), garantizará mejor cierto éxito en un mundo tan competitivo y globalizado como el que vivimos.
\end{abstract}

Palabras clave: diferencias territoriales, convergencia económica, descentralización.

\begin{abstract}
The population's irregular distribution in the Spanish regions continues increasing. The population has continued concentrating on the coastal regions and the Balearic islands and Canarys, besides Madrid, urban region, with a strong dynamism. In front of it the great space interior maintains its low densities. The group of the Spanish economy has grown with force. He has not made it same in all the regions, but rather it has allowed a slight tendency toward the regional convergence, in spite of the strongs regional differences. But, they are still numerous the regions that have a half level of inferior wealth to the average of the European Union. The autonomous decentralization has been quick and deep. It has been reached a situation similar to that of the Federal States. Face to the future a dual dynamics is observed: in front of that centrifugal political ideology, every time the eco-
\end{abstract}


nomy is sustained in a more integrated market, with better accessibility territorial and bigger cohesion. A future of unit territorial Spaniard ( peripheral space inside the European Union) will only guarantee certain success in such a competitive world and globalizing as which we live.

Key Words: Territorial differences, economic convergence, decentralization.

\section{Consideraciones de partida}

La organización territorial de cualquier Estado es siempre un aspecto clave. Dado que el territorio, junto a sus recursos humanos, en su sentido más amplio, son los elementos básicos de todo Estado, interesa sobremanera saber cómo se articula el modelo de relaciones y administración de los entes públicos en su proyección espacial. En la actualidad existen en torno a doscientos Estados. Si bien pueden encontrarse diferencias y matices numerosos, reflejo de una realidad muy compleja, en esencia cabe hablar de dos modelos básicos, unitarios y federados (García de Enterría, 1984); en nuestro caso, nos encontramos, en cierta forma, más cerca de los segundos.

Como hace años escribía Ortega y Gasset «todo lo que al hombre se refiere es histórico, lo histórico es inexorablemente cambio, vicisitudes y alternativa; mudanza de peor a mejor y de mejor a peor, angustia y alborozo, ventura y desgracia. Por tanto... el hombre tiene que vivir alerta y afanoso para realizar en la medida de lo posible ese programa intransferible de existencia que cada uno de nosotros es» (1973, p. 23). Pues bien, dentro de esa dinámica, los últimos lustros del siglo pasado y estos primeros años del que acaba de comenzar, están significando cambios acelerados en toda la organización planetaria. Caminamos con fuerza hacia una globalización, donde las partes del Planeta están más interrelacionadas; por lo cual los horizontes se abren y expanden, sobrepasando lo que durante siglos han sido otros escenarios (Giddens, 2003). Vivimos un mundo global, en él las comunicaciones instantáneas permiten contactos y realizaciones impensables hace muy poco tiempo. Ahora bien, para articular esta nueva realidad sólo se disponen de tradicionales estructuras de organización territorial, entre las cuales, las más perfectas y operativas continúan siendo los Estados; aunque se están ensayando nuevas formas; el caso de la construcción de la Unión Europea es una prueba de ello (Herrero de Miñón, 2004).

Quizás, ante ese panorama universal, - la aldea global que se ha dado en llamar-, numerosos colectivos humanos se siente perdidos y pretenden encontrar refugio en lo más cercano: el pueblo, la tribu (Breully, 1990). Así, con frecuencia, encontramos una situación contrastada, en la cual conviven y se opone una realidad global frente a la exaltación localista, a veces numantina y aldeana, en el más reducido sentido del término.

Hace un cuarto de siglo que España aprobó su Constitución democráticamente, con una mayoría aplastante de votos. Una de sus principales innovaciones fue su modelo de articulación territorial, plasmado en el Título VIII, además de otros artículos referidos al mismo, desde el propio Título Preliminar. Ello ha sido ocasión de numerosas celebraciones, análisis y reflexiones. Aquí, modestamente, sólo se pretenden aportar algunas consideraciones desde nuestra perspectiva geográfica, en esencia, en lo concerniente a sus aspectos territoriales.

\section{Continuación de las divergencias demográficas regionales}

Para cotejar los datos demográficos se ha recurrido a los censos de 1981 y 2001. Aunque la Constitución se aprueba en diciembre de 1978, y los primeros Estatutos de Autonomía y 
el acceso a través de la preautonmía, se realiza entre 1979 y 1982, parece conveniente partir de la misma fuente, tomando como referencia los dos periodos intercensales, separados por 20 años. Otra precisión terminológica que conviene añadir es que, si bien el término Comunidad Autónoma (CA) y en plural (CC.AA., para abreviar), hacen referencia a un concepto político-administrativo, que difícilmente encaja con las diferentes acepciones del polisémico región, se utilizan indistintamente uno y otro, dado su uso frecuente, habitual y coloquial.

En 1981 los contrastes demográficos, tanto en sus valores absolutos como relativos, eran acusadas entre las CC.AA.; esa desigualdad viene de muy atrás (Rodríguez, 1978 y 1985; Puyol, 1979). De un lado, los datos totales, se aconseja contemplarlos dentro de las diferencias territoriales notables existentes entre unas y otras entidades autonómicas. En el cuadro 1, segunda columna, pueden confirmarse tales valores. Eso se debe no sólo a sus disparidades de tamaño (siete son CC.AA. uniprovinciales, además de las ciudades autonómicas de Ceuta y Melilla, que acceden a tal condición recientemente, mientras que otras suman hasta nueve provincias). A su vez, las dimensiones de las provincias también son dispares. Por ello, (dejando aparte las dos ciudades autónomas, no tenidas en cuenta en las evaluaciones de valores absolutos, para evitar distorsiones), se advierte que entre la CA más extensa y la menos (Castilla y León y Baleares), se registra una proporción de 1 a 18,8.

Durante esas dos décadas, la población española ha aumentado 3,2 millones de personas. No es una cifra muy alta. Cabe añadir que es resultado, fundamentalmente, de la debilidad progresiva de su incremento natural, por el descenso continuo y acusado de la natalidad, junto a un cierto estancamiento de la mortalidad (Puyol, 1997; Serrano, 2003). Sólo durante los últimos años noventa, la llegada rápida y vigorosa de población inmigrante desde el exterior ha contribuido a incrementar el resultado del balance señalado (Muñoz; Izquierdo, 1989; Gozálvez, 1995).

Ese saldo global positivo no se ha repartido por igual entre todas las CC.AA. Doce de ellas, más Ceuta y Melilla, incrementan sus efectivos, frente a cinco que registran pérdidas netas, (véase el referido cuadro 1). Las mayores ganancias absolutas corresponden a: Andalucía, Madrid y Comunidad Valenciana. La suma de tales ganancias representan el 68,5\% del incremento total español. En el lado opuesto, los retrocesos más abultados se registran en Castilla y León, Galicia, Asturias y País Vasco. La adición de los citados retrocesos netos no son cuantiosos en sí mismos; sin embargo constituyen el claro síntoma de una tendencia de comportamiento de sus efectivos humanos; pues mientras que el conjunto nacional asciende durante los veinte años transcurridos en más de tres millones de personas, las referidas CC.AA. se descuelgan en su evolución, soportando retrocesos netos. Todo ello frente al signo opuesto, muy dinámico de otras. Un claro contraste.

Las causas de tales balances son numerosas y de diferente naturaleza; por tanto, imposible de analizarlas con detalle aquí (Cebrián, 1995). Sólo es factible, en consecuencia, hacer referencia a las más destacadas de manera muy sucinta:

a) Dentro de una disminución constante y progresiva de las tasas de crecimiento vegetativo, se advierten apreciables diferencias regionales. Mientras que en algunas CC.AA. se registran valores negativos o casi insignificantes aumentos (Asturias, Vascongadas, Castilla León, Aragón, Galicia, etc.), en otras, aún en los momentos de menores cifras, se mantienen valores varios puntos más altos (Murcia, Canarias, Andalucía, etc.).

b) De otro lado, los flujos migratorios interregionales han sufrido durante los últimos lustros cambios significativos, en referencia a periodos precedentes. Instalados en 


\section{Cuadro 1}

COMPORTAMIENTO DE ALGUNOS VALORES DEMOGRÁFICOS BÁSICOS, 1970-2001

\begin{tabular}{|c|c|c|c|c|c|c|c|c|c|}
\hline & $\begin{array}{c}\text { Extensión } \\
\mathrm{km}^{2}\end{array}$ & $\begin{array}{l}\text { Población } \\
\text { absoluta } \\
\text { en } 2001 \\
\end{array}$ & $\begin{array}{c}\text { Variación } \\
\text { neta, absoluta } \\
\text { 1981-2001 } \\
\end{array}$ & $\begin{array}{c}\text { Densidad } \\
\text { de población, } \\
1981, \mathrm{~h} / \mathrm{km}^{2} \\
\end{array}$ & $\begin{array}{c}\begin{array}{c}\text { Densidad } \\
\text { de población, } \\
2001 \mathrm{~h} / \mathrm{km}^{2}\end{array} \\
\end{array}$ & $\begin{array}{c}\text { Significación } \\
\text { \% sobre total, } \\
1981 \\
\end{array}$ & $\begin{array}{c}\text { Significación } \\
\text { \% sobre total, } \\
2001\end{array}$ & \begin{tabular}{|c|}
$\%$ residentes \\
nacidos en otra \\
C.A.,1981 \\
\end{tabular} & $\begin{array}{c}\text { \% residentes } \\
\text { nacidos en otra } \\
\text { C.A., 2001 } \\
\end{array}$ \\
\hline Andalucía & 87.595 & 7.357 .558 & 916.573 & 73,53 & 83,99 & 17,15 & 18.01 & 7,09 & 6,2 \\
\hline Aragón & 47.720 & 1.204 .215 & 7.263 & 25,08 & 25,23 & 3,19 & 2,94 & 16,32 & 16 \\
\hline Asturias & 10.604 & 1.062 .998 & -66.558 & 106,52 & 100,24 & 3,10 & 2,60 & 15,80 & 13,5 \\
\hline Baleares & 4.992 & 841.669 & 185.760 & 131,39 & 168,60 & 1,57 & 2,06 & 26,81 & 26,6 \\
\hline Canarias & 7.492 & 1.694 .477 & 326.831 & 182,55 & 226,17 & 3,32 & 4,14 & 9,59 & 7,8 \\
\hline Cantabria & 5.321 & 535.131 & 22.016 & 96,43 & 100,56 & 1,38 & 1,31 & 14,89 & 14,7 \\
\hline Castilla-La Mancha & 79.461 & 1.760 .516 & 111.932 & 20,75 & 22,15 & 5,11 & 4,30 & 10,38 & 13,3 \\
\hline Castilla y León & 94.224 & 2.456 .474 & -126.663 & 27,41 & 26,07 & 7,87 & 6,01 & 9,52 & 9,7 \\
\hline Cataluña & 32.113 & 6.343 .110 & 386.696 & 185,48 & 197,52 & 15,06 & 15,52 & 36,24 & 28,2 \\
\hline Com. Valenciana & 23.255 & 4.162 .776 & 515.998 & 156,82 & 179,00 & 9,08 & 10,19 & 25,22 & 21,5 \\
\hline Extremadura & 41.634 & 1.058 .503 & -6.465 & 25,58 & 25,42 & 3,45 & 2,59 & 7,76 & 8,6 \\
\hline Galicia & 29.575 & 2.695 .880 & -116.032 & 95,08 & 91.15 & 7,89 & 6,59 & 6,13 & 4,4 \\
\hline Madrid & 8.028 & 5.423 .384 & 736.489 & 583,82 & 675,55 & 12,48 & 13,27 & 45,68 & 36,6 \\
\hline Murcia & 11.314 & 1.197 .646 & 242.159 & 84,45 & 105,85 & 2,54 & 2,93 & 11,03 & 11,0 \\
\hline Navarra & 10.391 & 55.829 & 46.822 & 48,99 & 53,49 & 1,36 & 1,36 & 19,48 & 18,6 \\
\hline País Vasco & 7.234 & 2.082 .587 & -59.222 & 296,08 & 287,88 & 5,70 & 5,09 & 15,80 & 26,2 \\
\hline Rioja, La & 5.045 & 276.702 & 22.353 & 50,42 & 54,84 & 0,69 & 0,67 & 18,78 & 20,3 \\
\hline Ciudad Aut. Ceuta & 20 & 71.505 & 6.241 & 3263,20 & 3575.25 & 0,17 & 0,17 & s.d. & 23,3 \\
\hline Ciudad Aut. Melilla & 12 & 66.411 & 12.818 & 4466,08 & 5534,25 & 0,14 & 0,16 & s.d. & 20,4 \\
\hline Total España & 504.750 & 40.847 .371 & 3.283 .873 & 74,42 & 80,92 & 100 & 100 & & \\
\hline
\end{tabular}

Fuente: I.N.E.; La Caixa, Elaboración propia.

una tendencia general de apreciables flujos globales, se producen notorias variaciones e incluso cambios de tendencia (Cabré, 1985; Serrano, 1987 a; 1989; 1995). Así, regiones con saldos negativos constantes mantenidos durante décadas, consiguen ahora ganancias (Andalucía, Murcia, Extremadura, etc.). A la vez se dan situaciones opuestas, caso de aquellas regiones que fueron destino continuado para decenas de miles de inmigrantes (García-Barbancho, 1967 y 1988), ahora se convierten en áreas con saldos negativos (País Vasco, Cataluña, por ejemplo).

c) Un tercer aspecto destacado, de notable peso reciente, se debe a la inmigración procedente del exterior. Estamos hablando de una cifra que en datos contabilizados en el último censo, superaba ya el millón de personas, y sigue creciendo sin parar. Algunos sitúan su volumen a finales de 2004 en torno a los tres millones. Pues bien, el destino de estos inmigrante dista de ser regular entre las CC.AA. españolas. Mientras que es elevado en algunas (Cataluña Madrid, Valencia, Andalucía y Murcia), apenas cuenta en otras (Galicia, Castilla y León, País Vasco, Cantabria, Asturias, etc.).

La combinación plural y dispar de tales aspectos explica la evolución diferenciada de los efectivos demográficos regionales. Esas causas obedecen a diferentes motivaciones. No responden a algo fortuito ni ocasional. Se llega a ellas por otros motivos más profundos, sin 
duda muy complejos y de dispar naturaleza; en especial, de índole económica, productiva, sociológica y política; en cierta medida relacionados con la génesis y desarrollo del propio proceso autonómico.

Como consecuencia de la evolución diferenciada de los efectivos poblacionales, se han modificado también de manera dispar las densidades de población (véanse al respecto los datos de las columnas correspondientes del citado cuadro 1). La media española ha pasado de 74,4 a 80,9 h. $/ \mathrm{km}^{2}$. En referencia a esos valores medios se advierte que en 1981 eran diez las CC.AA. que la sobrepasaban, en tanto que las siete restantes registraban cifras inferiores. Por el contrario, en 2001 once CC.AA superan el promedio y seis no lo alcanzan. Las situaciones extremas se ha ampliado igualmente. Así, en 1981 las cifras máximas correspondían a: Madrid 583,8 y Castilla-La Mancha, 20,7; mientras que en 2001 la diferencia era aún mayor, si bien los protagonistas que encabezan y cierran la jerarquía eran los mismos (Madrid, 675,5 y Castilla-La Mancha, 22,1). Entre ambos extremos hay una variada gama de cifras. Simplificándolas se advierte como se ha ido afianzando el modelo, ya tradicional, de distribución desigual de la población en España, en el cual, son los dos archipiélagos (Baleares y Canarias), junto con los espacios de litoral, las regiones que sobrepasan la media española; frente a un amplio espacio interior, formado por ambas Castillas, Extremadura y las regiones del Valle del Ebro y aledaños, donde se contabilizan las menores densidades. Madrid y su importante y dinámica región urbana aporta una significativa excepción a tal dualidad básica. Este esquema inicial, afianzado a lo largo del Siglo XX (Rodríguez, 1985), con ligeras matizaciones ha seguido su tendencia en los últimos tiempos de creación, organización y asentamiento del sistema territorial autonómico

Otro aspecto que corrobora el ascenso de la divergencia en el comportamiento demográfico de las CC.AA. españolas durante su transcurso reciente se advierte al comprobar cuál a sido la modificación en su significación porcentual sobre el total nacional durante este periodo de tiempo. En el referido cuadro 1 se exponen los datos. Estos confirman las acusadas diferencias internas de las CC.AA.; la realidad plural, abarca desde la menos poblada (La Rioja), a la mayor (Andalucía). Precisamente ambas, a lo largo de esos veinte años, han aumentando sus diferencias; pues mientras Andalucía incrementa su porcentaje (+0,86 puntos); La Rioja desciende $(-0,02)$. Sólo hay una C.A., Navarra, además de Ceuta, con valores porcentuales de significación constante en 1981 y 2001. Las demás sufren alteraciones. Los mayores incrementos corresponden a: Comunidad Valenciana, 1,11 \%; Andalucía, 0,86; Canarias, 0,82; Madrid, 0,79; seguidas de: Baleares, 0,49; Cataluña 0,46 y Murcia 0,39. En el lado opuesto, las que reducen su significación porcentual son: Castilla y León, -1,86; Galicia -1,28; Extremadura -0,86; Castilla-La Mancha -0,81; País Vasco 0,61 ; Asturias $-0,50$ y Aragón -0,25. Cantabria y Melilla casi permanecen estables, con balances de: $-0,07$ en la primera y $+0,02$ en la segunda.

A través de esos comportamiento se confirma que ciertas CC.AA. afianzan su peso demográfico sobre el conjunto español, tal sucede con Andalucía, Cataluña, Madrid y Comunidad Valenciana. La suma de las cuatro significan el 56,99\% del total nacional, mientras que la dimensión de sus territorios sólo ascienden al 29,86 \%. Tal concentración de efectivos humanos, frente a un peso demográfico que se reduce progresivamente en otras CC.AA., corrobora la creciente divergencia de la distribución poblacional sobre el territorio. En suma, una parte de España, la más extensa, pierde significación en el volumen de sus efectivos humanos, frente a otra, donde se concentran cada vez mayor proporción de los mismos.

Las consecuencias de esta dinámica divergente son preocupantes en todos los aspectos. Sobre todo, si pensamos que en los países avanzados, los recursos humanos, su número y calidad, constituyen el principal activo. Además, esa divergencia creciente conlleva nume- 
rosos efectos añadidos en todo lo que tiene que ver con la ordenación territorial, la propia organización y distribución de las infraestructuras de transporte, etc. De sobra es conocido que una realidad homogénea en este apartado, sólo se encuentra en postulados teóricos; pero, igualmente, resalta que una situación tan contrastada como esta, y con tendencia a acrecentar sus disparidades, es algo sobre lo que deberían intervenir los poderes públicos (dentro de sus posibilidades), intentando corregir o mitigar esos desequilibrios. Pero, a nadie se oculta que, la propia estructura territorial del Estado, junto a los rasgos básicos de nuestro modelo económico predominante, contribuyen a dificultar políticas de mayor equilibrio en tal sentido.

Los flujos migratorios interregionales y sus dispares tendencias durante los últimos lustros, aspectos ya apuntados, no ayudan a mitigar las acusadas diferencias demográficas existentes; si bien están contribuyendo a incrementar el porcentaje de «autoctonía» de cada una. Como se especifica en las dos columnas correspondientes del cuadro 1, la mayoría de las regiones españolas han reducido, al paso de las dos últimas décadas, la proporción de personas residentes en cada una, nacidas en otras C.A. Sólo algunas CC.AA. contabilizan ligeros ascensos, poco significativos. Así y todo, en el 2001 las diferencias que mostraban las CC.AA. son contrastadas. Frente a las proporciones más altas aportadas por Madrid, $36,6 \%$; Cataluña, 28,2 \%; Baleares 26,6 \% y Comunidad Valenciana, 21,5\%, se oponen otras donde esa proporción es modesta: Galicia 4,4 \%; Andalucía 6,2 \%; Canarias 7,8 \%; Extremadura 8,6 \% y Castilla y León 9,7\%.

En otro orden de cosas, resulta poco comprensible ver las diferencias tan abultadas de paro entre las regiones españolas, pues mientras en varias de ellas se mantienen cifras elevadas algunas han conseguido una situación de casi pleno empleo, y con entradas copiosas de inmigrantes desde el exterior. Sin embargo, ello no es suficiente para generar mayores flujos migratorios interregionales. Para comprender tal realidad puede ayudar una situación donde participan con fuerza valoraciones de topofilia y apego excesivo al terruño, - favorecida e impulsada, acaso, por la propia organización y estructura territorial - , además, por supuesto, de otras cuestiones de diferente naturaleza, entre las que intervienen: ayudas sociales, subsidiaciones crónicas y demás comportamientos poco efectivos, sin embargo, para disminuir el desempleo.

\section{3. ¿ Hacia una ligera convergencia económica regional?}

Es un asunto complejo calibrar el nivel de riqueza económica de las diferentes unidades territoriales de cualquier país. Sin duda, uno de los aspectos que dificulta esa labor es contar con bases de datos continuados, regulares y solventes que permitan su evaluación ajustada. También es necesario señalar, para proceder a esa tarea, la posibilidad de emplear diferentes modelos, fórmulas y procedimientos; pues, de acuerdo con ello, los resultados pueden ser dispares (Cuadrado, 1998). Sin embargo, no hay que insistir, dada la importancia del tema y desde hace tiempo, ha sido un objetivo básico del que se han ocupado, en especial, las disciplinas económicas (García Barbancho, 1979; Cuadrado, 1987; Martín, 1990); también, debido a su trascendencia espacial, desde la Geografía son motivo de atención (Higueras, 1980; Alonso, 1990). Igualmente, conviene no olvidar que la homogeneidad territorial en esas cuestiones es un mito; pues en todos los Estados del Planeta, en especial en aquellos que abarcan una cierta dimensión, las diferencias territoriales son una realidad siempre presente (Boudeville, 1961; Coraggio, 1985; Oliver, 2002). Pero ello no es impedimento, sino todo lo contrario, constituye un estímulo, intentar acortarlas (Boudeville, 1966), aunque se trate de una tarea harto difícil y de resultados inciertos (Gámir, 1999). Tal aspecto considero que encierra un gran interés, dentro de lo que constituye un objetivo central de 
este trabajo, aunque por su dimensión y características sólo es posible hacer unas breves y sucintas referencias, sin poder profundizar siquiera en determinadas cuestiones, que sólo se apuntan.

Conviene partir de una idea central: durante el periodo temporal abordado el conjunto de la riqueza económica española ha conocido un espectacular crecimiento. En valores absolutos corrientes ha pasado entre 1980 y 2002 de 91.061 millones de euros a 626.249 en 2002. Para calibrar ese enorme ascenso, basta considerar que el valor 100 de 1980 pasa a 314,9 en 1990 y en 2000 se eleva hasta 603,5; la del último año (2002) asciende a 687,8. Por otro lado, dado que el incremento de la riqueza se ha realizado a mayor ritmo que el de la población, los indicadores por persona también han incrementado con fuerza. Así en 1980 se puede calcular que significaban 2.412 euros; pasan a 7.272 en 1990; suman 13.569 en 2000 y se contabilizan 14.970 en 2002. Estableciendo el mismo cálculo relativo, el valor cien de la proporción referida a 1980, se ha convertido en 620,6 en 2002. De todas maneras interesa matizar que esas cifras se refieren a precios corrientes, de los cuales conviene deducir los costes que la inflación ha ido descontando en ese tiempo.

Con todo, el balance del periodo es muy positivo como señalan las cifras aportadas; los valores globales se multiplican por más de seis veces, a la vez que los indicados per cápita también se aproximan a esa proporción. El contexto del entorno español ha sido favorable, al tiempo que la política económica española seguida se ha mostrado capaz de ir sorteando las no pocas dificultades planteadas. De todas maneras conviene recordar que en el transcurso de ese tiempo se suceden fases diferenciadas de evolución económica; lo cual recuerda que las bases de nuestra economía no son tan sólidas ni tan firmes, como esos datos generales pueden aparentar.

Así mismo, el empleo de los datos referidos camuflan lo que ha constituido y, en parte sigue vigente, un problema estructural de nuestra economía: la tasa de inflación elevada. Casi siempre es superior a la de nuestros vecinos europeos, incluso, no han faltado los años en que sobrepasó ampliamente su promedio; ello, junto a otros aspectos, aconsejó realizar varias correcciones devaluadoras de la moneda nacional, además de otras graves distorsiones en el conjunto del sistema productivo (Fuentes Quintana, 1988). También resulta de gran interés cotejar la convergencia real de la economía española con el promedio Comunitario. Ello permite calibrar mejor la ritmo de comportamiento y evolución de España, y sus CC.AA., en referencia al conjunto de la Unión.

El balance de tal comparación no resulta tan optimista. Pues en el momento del inicio de nuestra transición política (1975) el promedio del PIB español per cápita significaba el $81,39 \%$ del Comunitario; una década más tarde (1985) se había retrocedido más de 10 puntos, situándose en el 70,60 \% del promedio de la Unión. Dos lustros después, en 1995 aún no se había alcanzado el nivel de referencia existente en 1975, ya que ascendía al 79,17\% . Por consiguiente, la convergencia real, sólo asciende de nuevo, con más fuerza y de forma ininterrumpida a partir de 1995. Desde esa fecha el promedio de crecimiento de la economía española supera al de la Unión Europea, lo que ha permitido ir acortando distancias (Serrano; Calmés, 1998); Así, en 1999, cuando se contabiliza el 83,17 \%, se supera por primera vez la proporción inicial existente en 1975. En 2004 se evalúa el PIB per cápita español en cifras situadas en torno al $90 \%$ del Comunitario. Por otro lado, no debe olvidarse que se está comparando el devenir español con el de un conjunto económico próspero y dinámico, el conjunto de la Unión Europea; de ahí que no resulta nada sencillo acortar distancias con él. Por eso, el panorama de alcanzar una convergencia real con ella se presenta, por el momento, como una meta difícil de conseguir, a corto plazo.

Pues bien, dentro de ese panorama general es preciso situar el devenir de las diferentes CC.AA. que ha sido, según se expone a continuación, muy diferente entre sí (Villaverde, 
2001). Simplificando en extremo el asunto, se utiliza como criterio de referencia la evolución del PIB per cápita entre 1975, año de inicio de la transición, y 2002, última fecha de la que se dispone de información. Sobre lo ocurrido en ese tiempo y de las disimilitudes que muestran los valores referidos a las diferentes CC.AA. y su dispar evolución, conviene precisar lo siguiente:

a) En 1975, en vísperas de los inicios de la andadura autonómica, la jerarquía de las regiones españolas era marcada. Tomando como referencia media el valor nacional, igual a 100 , la que ocupaba una posición zaguera, Extremadura $(57,65 \%$, y la más avanzada, País Vasco, 133,97 \%), existía una diferencia de 76,32 puntos. En 2002, las disparidades extremas corresponden a Madrid (quien encabeza la jerarquía) con 127,0 y Extremadura, 70,07; es decir 56,30 puntos de margen; lo cual, como balance de ese tramo temporal, representa una reducción de 19,86 puntos. Se acortan, pues, significativamente la distancia entre los valores extremos.

b) Por otro lado, en 1975 (trasladando la actual organización territorial a ese momento), eran nueve las entidades que superaban el promedio nacional, quedando las 10 restantes por debajo. En 2002 tal comparación se había alterado poco (ocho superaban el promedio nacional y once quedaban por debajo del mismo). Una situación muy similar, a pesar de los años transcurridos.

c) No obstante, las variaciones contabilizadas en las unidades territoriales son apreciables. Las que consiguen mejores resultados de aumento de su nivel de PIB son: Melilla, 14,29\%; Extremadura, 13,05 \%; Castilla y León, 10,45 \%; Galicia 9,32 \%; Navarra 9,07 \% y La Rioja, 8,57 \%, seguidas de Ceuta, Aragón, Canarias, CastillaLa Mancha, Andalucía y Comunidad Valenciana. En el lado opuesto, los retrocesos más fuertes se registran en: Asturias -15,62 \%; País Vasco -15,37 \%; Cantabria $10,94 \%$; Madrid, -6,81\%; Cataluña $-5,48 \%$, Baleares y Murcia.

d) Así mismo, la diferencia entre la región más distante, a la baja, del promedio nacional, era en 1975 de 42,35 puntos, en 2002 se reduce a 29,30, lo cual denota una cierta mejora. De manera complementaria, utilizando el mismo promedio nacional, en la parte superior de la jerarquía, la disparidad se acorta también en 6,81 puntos, al pasar de 133,97 puntos a $127,0 \%$.

De lo antes expuesto se deducen tres reflexiones llamativas:

$1^{\text {a) }}$ El crecimiento general conseguido por la economía española incide de muy diferente forma entre sus unidades territoriales. Mientras unas aprovechan ese tiempo para mejorar su situación, en referencia al promedio nacional; otras, por diferentes causas, se ven sometidas a notables retrocesos. Así, entre la CA que más aumenta su significación porcentual, y la que más retrocede, corresponde una diferencia de 29,91 puntos \%. Por ello, se contabilizan en el transcurso de ese periodo temporal alteraciones significativas de ambas relaciones jerárquicas, tanto en los lugares de cabeza como en los zagueros.

$\left.2^{\mathrm{a}}\right)$ Espacialmente se comprueba la consolidación de ciertas tendencias territoriales, de tal suerte que las mayores ganancias de este indicador corresponden a las CC.AA. situadas por lo común, entre los puestos postreros en este indicador económico. Eso es palpable en Melilla, Extremadura, Galicia y Ceuta, de manera más llamativa. Acaso esto puede interpretarse como una consecuencia de que el nuevo sistema territorial favorece la mejora de los que se encuentran en tal situación, dada la acción compensadora, equilibradora y subsidiaria del Estado (Castells, 2000). Al mismo tiempo se advierte como otras CC.AA. que ya disfrutaban de niveles de renta medios, han logrado en esos años mejorar su situación sustancialmente; me refiero, 
por ejemplo, a Navarra, La Rioja y Aragón; aunque anótese que todas ellas se caracterizan por haber tenido un incremento demográfico débil; lo cual ayuda al ascenso de los valores per cápita. No es ese el caso de Canarias y Comunidad Valenciana, las cuales, con ascensos mayores de población, también mejoran su situación en la jerarquía de riqueza analizada.

$3^{\text {a }) ~ E n ~ e l ~ l a d o ~ o p u e s t o, ~ l o s ~ m a y o r e s ~ r e t r o c e s o s ~ c o i n c i d e n ~ c o n ~ C C . A A . ~ d e ~ l a ~ f r a n j a ~ c a n t a ́-~}$ brica, en varias de ellas alcanzaba especial significación un modelo de economía basada en determinados sectores y activos industriales, que contribuyeron en su momento a alcanzar niveles de riqueza apreciables. La crisis de algunos de ellos, junto a otros plurales y complejos elementos, ha contribuido a su retroceso posterior. Descensos menores registran ciertas CC.AA. que partieron y mantienen mejores niveles de PIB por habitante, caso de Madrid, Cataluña y Baleares. Acaso, su situación inicial favorable, dificulta seguir aumentando al mismo ritmo el incremento de riqueza. (Villaverde; Pérez, 1996).

Por tanto, de todo lo antes indicado es posible deducir que se perciben ciertos datos de los cuales se deduce una ligera tendencia hacia la convergencia económica de las regiones españolas, todo lo cual puede considerarse esperanzador.

Tras ese mismo objetivo de análisis, expuesto lo anterior, considero que resulta de gran interés, evaluar cuál ha sido el comportamiento de las regiones españolas, dentro del contexto más amplio que nos proporciona la Unión Europea, con el fin de perfilar más la evolución económica de las CC.AA. De manera sucinta pueden añadirse los siguientes aspectos más destacados referidos a tal devenir:

i) En 1975 sólo había cuatro CC.AA. que superaban el nivel medio del PIB Comunitario (valor 100): Baleares, 109,0 \%; Madrid, 108,88: País Vasco, 108,07 y Cataluña, 104,03. Las restantes quedaban por debajo de ese nivel. Incluso algunas ni siquiera significaban la mitad; Extremadura. Así mismo, varias CC.AA. ofrecían valores inferiores al $75 \%$ de la Comunidad Europea: además de Extremadura, 47,12 \%; Andalucía, 59,46; Galicia, 62,01; Castilla-La Mancha, 63,57; Canarias, 66,12; Murcia, 67,60; y Castilla y León, 68,32; junto a las ciudades autónomas: Ceuta y Melilla. Un panorama, por tanto, significativo, que confirma el atraso económico marcado de buena parte de España.

ii) En 2002, habiendo mejorado algo las cifras generales, sin embargo, sólo cinco CC.AA. superaban el promedio de la Unión (valor 100): Madrid, 111,5 \%; Baleares,109,0\%; Navarra, 108,3; Cataluña, 107,4 y País Vasco, 104,1. De ellas, Navarra consigue estos años un avance mayor, ascenso de 15,66 puntos; otras tres mejoran su situación: Cataluña, 3,37; Madrid, 2,62 y Baleares, 1,0; en tanto que País Vasco, retrocede sobre su significación porcentual previa, -3,97 puntos. En valores netos, otras numerosas regiones consiguen notables incrementos, mejorando su situación relativa con el promedio Comunitario; resaltan: Melilla, 16,18; La Rioja, 14,8; Castilla y León, 14,68; Galicia, 12,69; Aragón, 11,39; Extremadura, 10,88; Canarias, 10,28 , etc.. Pero, así y todo, se partía de un nivel tan modesto en muchas de ellas que, aún en 2002, son varias las que continúan por debajo del $75 \%$ del promedio de la Unión: cinco CC.AA. (Andalucía, Extremadura, Castilla-La Mancha, Galicia, y Murcia, además de Ceuta y Melilla).

iii) Como se ha apuntado antes, ello es consecuencia directa de que en ese plazo de tiempo, si bien catorce CC.AA. logran mejoras en relación al promedio de la Unión, más Ceuta y Melilla, otras retroceden, como: Asturias, País Vasco y Canta- 
bria, con valores respectivos: -5,72, -3,97 y -3,16; distanciándose de la situación existente en el punto de referencia inicial. Todo eso se advierte, a pesar de que como consecuencia del ingreso en 1986 de España en la Comunidad Europea, son cuantiosas las ayudas recibidas por dispares conceptos, dentro de la política territorial europea que intenta mitigar esas diferencias regionales, propiciando una mayor cohesión y convergencia.

iv) La previsión calculada en 2005, con todas las cautelas que ello impone, permite abrigar cierta esperanza de seguir mejorando el balance general hacia una mayor convergencia. En ese horizonte cercano se prevé que siete CC.AA. sobrepasarán el nivel medio de riqueza de la Unión Europea. Si se cumple, eso representa una mejora notable. Pero, así y todo, para tal fecha aún restarán varias CC.AA. con un nivel de PIB inferior al $75 \%$ de la Unión: Extremadura y Andalucía serían las más desfavorecidas con cifras estimadas en $59 \%$ y $67 \%$ respectivamente. Queda por ver si en el futuro, los fondos de ayuda de la Política Comunitaria Europea continuarán de forma similar al de los últimos años (Mella, 1998), o bien como casi todo hacer pensar y se barrunta, se reducirán de manera drástica.

Así es posible deducir que, si bien se ha producido una mejora general y cierta convergencia económica de la mayoría de las CC.AA. entre sí y en referencia a los valores medios de la Unión, es aún largo el trecho que queda por recorrer para que una parte importante de España deje de estar entre las regiones más desfavorecidas del conjunto Comunitario. La reciente ampliación de la Unión camufla esa cruda realidad

Complementariamente con lo antes indicado conviene también fijarnos en otros aspectos que aportan mayor conocimiento a todo ello. Se trata de comprobar las modificaciones sufridas en lo que representa el PIB de cada unidad territorial española, sobre el total, expresado en valores porcentuales. Debido a la disímil significación de las CC.AA. españolas, en su volumen de población y nivel económico, su participación en el conjunto nacional es muy contrastada. Dejando de considerar las dos ciudades autónomas, por su singularidad y reducido peso demográfico, y manteniendo el sistema de trabajo seguido, de trasladar a 1975 los valores de las entidades territoriales autonómicas actuales, entre la cuota de participación de Cataluña y La Rioja se contabilizaban 19,30 puntos de diferencia. En 2002 se había recortado algo la disimilitud, quedando la diferencia (entre esas mismas dos CC.AA.), en 18,20 . En el transcurso de ese periodo se registran variaciones apreciables. Nueve CC.AA. incrementan su cuota de participación dentro del conjunto nacional, en tanto que las ocho restantes la reducen. Entre las primeras sobresalen por sus mejores resultados: Comunidad Valenciana $+1,10$ puntos; Canarias $+0,89$; Madrid $+0,88$; Andalucía $+0,71$, Baleares $+0,49$; Murcia $+0,27$; Navarra $+0,16$; La Rioja $+0,10$ y Extremadura $+0,03$. Por el contrario, las que más retroceden son: País Vasco -1,60; Cataluña -1,0 y Asturias.-0,85.

De lo anterior se infiere que a pesar de esas modificaciones sigue habiendo diferencias muy acusadas entre las CC.AA. Por otro lado, no se deben extraer conclusiones cerradas, aunque parece confirmarse que durante los últimos años, la evolución regional de las magnitudes económicas básicas, muestran un ligera reducción de las diferencias interterritoriales, abriéndose una tímida tendencia hacia su mayor convergencia. El comportamiento general positivo de la economía española ha favorecido ese devenir, a la vez que la mayor integración de todo nuestro sistema productivo dentro del conjunto Comunitario, impulsado por nuestra entrada en la Unión (Casella, A., 1996).

De igual manera la propia organización autonómica, con la adquisición progresiva de competencias y el incremento de su protagonismo ha tenido una consecuencia favorable en el devenir común, evitando una progresiva alza de los desequilibrios territoriales. Ello se 
lleva a cabo, en esencia, mediante un proceso plural y complejo, que puede esquematizarse en varios rasgos básicos:

$\left.1^{\circ}\right)$ La creación de los gobiernos autonómicos y todo el proceso de «construcción de regiones», con lo que significa en su sentido más amplio, ha significado un despertar de nuevas energías y ha contribuido a avivar una sana competitividad en numerosos sectores productivos. Lo cual puede considerarse como algo favorable. La construcción de nuevas infraestructuras de transporte para vertebrar mejor los territorios regionales, constituyen igualmente un ejemplo claro de mejora ( Mas; Maudos; Pérez; Uriel, 1996).

$2^{\circ}$ ) Así mismo, el protagonismo autonómico creciente ha favorecido que la acción general del Estado, directa e indirecta, no pudiese llevarse a cabo de manera discrecional, ni tan a las claras, favoreciendo en exceso a unos territorios en detrimento de otros. Cada vez resulta más necesario contar con la conformidad de los entes autonómicos en las tareas de ámbito nacional; esto, aunque sea a «sensu contrario», impide situaciones de disparidad creciente; aunque la disimilitud de las unidades territoriales propicia equilibrios precarios e incluso origina presiones irregulares.

$3^{\text {a) }}$ Pero, según a se ha apuntado, creo que una gran parte de las actividades orientadas hacia la convergencia, o al menos a evitar mayores divergencias económicas territoriales, se deben a la propia política realizada o auspiciada desde el Estado (Jaén; Molina, 2001). Bien directamente, a través de su actividad inversora (la construcción de infraestructuras de toda índole, por ejemplo); o gracias a políticas económicas orientadas de pleno hacia el equilibrio (Fondo de Compensación Interterritorial). A pesar de que dado el sistema económico existente en toda la Unión, no es posible una planificación ni actuaciones directas de mayor enjundia, pues se considerarían como desleales y lesivas para los propios fundamentos del sistema..

$4^{\circ}$ ) De la misma manera, la política estatal, a través de sus diferentes gobiernos, conscientes de la realidad y gravedad de la cuestión, han defendido y obtenido, en el foro Comunitario, el aumento y la diversificación de políticas de ayuda e impulso hacia las regiones más desfavorecidas, propiciando así una mayor convergencia de las economías regionales.

$5^{\circ}$ ) En definitiva, los mecanismos del Estado, a través de su capacidad de redistribución, posibilitan y ayudan que la percepción y disponibilidad final de rentas familiares sea menos contrastada de lo que correspondería a las entidades territoriales; dados los contrastes de riqueza existentes en las CC.AA. españolas (Uriel, 2002). A pesar de la insolidaridad y reticencias que muestran ciertas CC.AA y el dispar apoyo recibido, desde algunas que son más directamente beneficiadas. .

$\left.6^{\circ}\right)$ Merced al impulso de la política estatal se ha conseguido en España, por primera vez en su historia, unas condiciones aceptables de integración del conjunto de la economía y el mercado nacional, con todo lo que ello significa de potencial de crecimiento. No hay que olvidar las dificultades orográficas y la topografía accidentada de gran parte del territorio español. Pues bien, por citar sólo un ejemplo, España ha pasado de disponer de $883 \mathrm{~km}$. de vías terrestres rápidas de gran capacidad (entre autopistas y autovías) en 1975, un valor modesto en 1980: $1993 \mathrm{~km}$., a más de 12.000 en los inicios de 2004. La gran «conectividad» que ello representa, inherente a la significación de este modo de transporte, es todo un símbolo, de la nueva realidad nacional (Serrano; Schliephake, K., 2004). El propio tráfico interior de pasajeros mediante el modo aéreo se ha incrementado desde 1980 a 2004 de manera sorprendente, al pasar de 23,3 millones de pasajeros a más de 70. En definitiva, gracias a la política de ámbito nacio- 
nal, se han creado las bases para el impulso del mercado español, real y efectivo, de gran repercusión en las empresas españolas. De manera paralela el conjunto del sistema productivo se ha abierto con fluidez hacia el resto de la Unión, penetra y se incorpora cada vez con más intensidad en otros horizontes mayores.

En el lado opuesto, creo que es oportuno hacer dos reflexiones complementarias:

a) En varias regiones se presentó el acceso a la autonomía como si fuese el «bálsamo de fierabrás», la medicina milagrosa que con inusitada rapidez iba a solucionar todos los problemas. Algunos fantaseaban diciendo que tal o cual región más atrasada, se iba a convertir en pocos años en «la California de Europa»; etc. Pasado un cuarto de siglo, se ve que eso sólo eran ilusiones ingenuas o especulaciones interesadas. Es difícil saber si tales afirmaciones se debían a mera ignorancia, a la estulticia de unos o a la mala fe de otros; o, acaso, al propio interés de beneficio particular buscado, por terceros.

b) Por desgracia se advierten numerosos y crecientes recelos entre las CC.AA. españolas. Los ejemplos de insolidaridad, las quejas y las inquinas, abundan cada vez más. Creo que la lógica y legítima confrontación política, se desvirtúa e impregna de cuestiones que afectan a toda España; sin embargo, a menudo, son tratadas desde intereses locales. Sólo desde una visión de Estado, considerando el conjunto nacional español, es posible encarar y hacer realidad un futuro deseable: una progresiva y mayor convergencia de las economías regionales.

\section{Rapidez y naturaleza de la descentralización político-administrativa}

El modelo territorial contemplado en la Constitución de 1978 emprendió una vía innovadora y, en cierta medida, atípica (Sánchez Agesta, 1980; García de Enterría, 1987). Pronto inició un auténtico y rápido proceso de consolidación. Sólo algunos, desde posiciones singulares, no calibraron el alcance del camino emprendido (Beneyto, 1980). Transcurridos cinco lustros desde sus inicios, los numerosos indicadores que pueden emplearse al respecto confirman lo acaecido. Así, por ejemplo, cuando contemplamos cuál ha sido el devenir y la realidad presente, de la estructura del sector público, según los niveles de gobierno, se constata el profundo e intenso cambio registrado:

Cuadro 2

ESTRUCTURA DEL SECTOR PÚBLICO POR NIVELES DE GOBIERNO EN ESPAÑA En porcentajes de gasto público total consolidado

\begin{tabular}{|c|c|c|c|c|}
\hline & $\begin{array}{c}\text { Gobierno } \\
\text { central }\end{array}$ & $\begin{array}{c}\text { Gobiernos } \\
\text { autonómicos }\end{array}$ & $\begin{array}{c}\text { Gobiernos } \\
\text { locales }\end{array}$ & Total \\
\hline 1979 & 88,0 & 0,1 & 11,9 & 100,00 \\
\hline 1985 & 76,6 & 12,6 & 12,8 & 100,00 \\
\hline 1990 & 67,5 & 19,2 & 13,3 & 100,00 \\
\hline 1995 & 67,0 & 21,5 & 11,5 & 100,00 \\
\hline 1997 & 63,8 & 23,9 & 12,3 & 100,00 \\
\hline $2004^{*}$ & 52,0 & 32,0 & 16,0 & 100,00 \\
\hline
\end{tabular}

Fuente: Dirección General de Coordinación con las Haciendas Territoriales (Ministerio de Economía y Hacienda. (*Estimación). 
En ese tiempo los Gobiernos Autónomos han pasado de su creación a ejecutar un porcentaje de gasto superior al $30 \%$ del total de los presupuestos públicos. Por el contrario, en otra escala de descentralización mayor, la que representan los Gobiernos Locales, sólo han crecido durante esos años un $4 \%$. De esa forma, la estructura del gasto público en España, atendiendo a sus diferentes niveles territoriales, se asemeja bastante a la de aquellos Estados, de estructura federal, más descentralizados del Planeta; tal y como puede cotejarse con los datos especificados en el cuadro siguiente

Cuadro 3

ESTRUCTURA DEL SECTOR PÚBLICO POR NIVELES DE GOBIERNO EN DISTINTOS PAÍSES FEDERADOS

En porcentaje del gasto público total consolidado

\begin{tabular}{|l|c|c|c|c|}
\hline & $\begin{array}{c}\text { Gobierno } \\
\text { central }\end{array}$ & $\begin{array}{c}\text { Gobiernos } \\
\text { intermedios }\end{array}$ & $\begin{array}{c}\text { Gobiernos } \\
\text { locales }\end{array}$ & Total \\
\hline Australia (1996) & 53,5 & 40,6 & 5,9 & 100,00 \\
\hline Canadá (1991) & 40,4 & 40,8 & 18,8 & 100,00 \\
\hline Estad. Unidos (1995 & 54,4 & 21,6 & 24,0 & 100,00 \\
\hline Alemania (1996) & 62,1 & 20,7 & 17,2 & 100,00 \\
\hline Suiza (1995) & 51,5 & 27,7 & 20,8 & 100,00 \\
\hline Media sin ponderar & 52,4 & 30,3 & 17,3 & 100,00 \\
\hline
\end{tabular}

Fuente: Government Finance Statistics Yearbook, International Monetary Fund.

Salvo algunas pequeñas diferencias, los valores españoles confirman una similitud evidente con todos ellos. Eso quiere decir que, a no ser que se camine en otra dirección, o se intente crear un «nuevo modelo singular en el Planeta», no queda prácticamente campo de maniobra para seguir avanzando en esa línea descentralizadora. Otra cosa bien diferente es que, dentro de esa tendencia, se reacomode y reorganice la descentralización existente; en especial resta bastante campo de acción, si se procede desde lo que ahora corresponde a los poderes autonómicos hacia los locales. Pues no es fácil pensar que un Estado pueda seguir operativo y eficaz con una reducción aún mayor de su capacidad económica de gobierno y gestión a la ahora disponible.

Otro criterio muy significativo que puede utilizarse para comprender la dimensión real del cambio experimentado por la organización territorial española lo encontramos en el número total de personas que trabajan para las Administraciones Públicas. Los acusados cambios registrados durante los últimos años son palpables. De una parte, se ha producido un aumento notable de su número total; entre 1982 y 2003 se pasa de 1,15 millones a 2,32; duplicándose la cifra global, al incrementarse en 1,17 millones las personas trabajando para las Administraciones Públicas. Incluso si comparamos lo que representa la proporción de funcionarios, en referencia a la población total, o a la población activa ocupada (habiendo crecido bastante esta última), se advierte un significativo ascenso. La segunda proporción sube de $10,04 \%$ a $13,75 \%$. No considero que tal incremento deba achacarse en exclusiva a la puesta en funcionamiento de las nuevas Administraciones Autonómicas - aunque han sido las que más han aumentado - ; más bien creo que, en su conjunto, debe pensarse que el ascenso de la riqueza nacional ha permitido reforzar los diferentes aspectos del Estado social y del bienestar, lo cual implica mayores necesidades de servidores públicos (Johnson, 1990). 
Tal vez más que ese incremento señalado, lo que destaca del balance funcionarial es que el Estado ha ido reduciendo su participación dentro del conjunto de la Función Pública, mientras que las CC.AA. de manera rápida, constante y creciente, pasan a convertirse en las mayores ocupadoras de personal funcionario, para atender sus nuevas competencias. En los años transcurridos (1982-2003) sus empleados pasan de 44.475 a 1,23 millones. En valores porcentuales, acaso más expresivos, parten de significar el 3,85\% sobre el total en 1982 al $52,89 \%$ de 2003. Por eso, cada vez resulta menos justificado achacar al poder central, ciertas carencias o deficiencias de funcionamiento de servicios gestionados por cada entidad autónoma. Ahora son ya las nuevas Administraciones Autonómicas, más próximas y cercanas al ciudadano, quienes deben atender correcta y adecuadamente sus necesidades. Tampoco parece posible ni riguroso pensar que pueda continuar el proceso de incremento funcionarial, ni de transferencias, con independencia de que sea posible realizar leves retoques, dado que la casi totalidad de lo contemplado en el texto Constitucional, en tal sentido, se ha llevado a efecto. Otra significación adquieren las reivindicaciones y demandas, de diferente naturaleza, propugnadas por determinadas fuerzas políticas en algunas regiones españolas.

Resulta útil, tras el cuarto de siglo transcurrido desde que se inició el proceso preautonómico y autonómico, y dado su devenir político-administrativo, recapacitar acerca de lo que ha significado la transformación de su estructura organizativa, su capacidad de gasto e inversión. Conviene plantearse algunas reflexiones sobre lo que todo ello ha representado para la nueva articulación del sistema territorial español. Es indiscutible que las actuaciones de las nuevas autoridades regionales españolas han puesto en marcha un proceso - si bien diferenciado entre sí-, de creación y asentamiento de las nuevas entidades territoriales (Serrano, 1993 y 1994, a). No hay que olvidar que, ante todo, una región se sustenta en una vivencia común compartida por la mayoría de sus ciudadanos, basada, entre otros aspectos, en la articulación territorial propia inherente al espacio vivido (Fremont, 1976); así como en el deseo de pertenencia y participación en él (Dumolard, 1975; Juillard, 1962 y 1974). Parece cierta la existencia de una heterogeneidad y variedad territorial apreciable, lo cual aconsejaba que esa pluralidad se extendiera a ciertos aspectos de diferente naturaleza (Del Campo; Navarro; Tezanos, 1977). La variedad se refiere tanto al medio natural (Floristán, 1988); como al de conciencia regional (Jiménez, 1977). No procede aquí, ni ahora, plantearse el procedimiento seguido ni el resultado numérico y material de las unidades resultantes; pero bien podría haber sido un número mayor o más reducido (Clavero,1983; Alonso, 1988). Ahora bien, es obligado recodar que la unidad territorial básica de partida, fue la provincia (Bradshaw; Estébanez, 1985; García Álvarez, 2002); una entidad espacial que camina hacia sus dos siglos de vigencia; de gran éxito y fuerte arraigo en el conjunto de la población española (Burgueño, 1986), a pesar de su dudosa consideración por algunos.

La importancia que desempeña en toda articulación territorial estatal la trama, morfología y jerarquía de las redes urbanas, y el funcionamiento de sus subsistemas de ciudades es enorme. La literatura geográfica es abundante e ilustrativa al respecto, a la vez que goza de cierta tradición (Dickinson, 1961; Marshall, 1987; Herbert; Thomas, 1990; Cori, 1995; Corna Pellegrini, 1995). Pues bien, aquí en España, se ha realizado un proceso de consolidación regional y una apreciable remodelación de los nuevos subsistemas urbanos regionales, desde los inicios de la andadura autonómica, a medida que tales entidades han ido tomando consistencia (López, 1985; Serrano; King; 1994, b). Pero, todo esa enorme y continuada tarea ha precisado, y se continúa en tal quehacer, cuantiosas inversiones, en plurales infraestructuras, para conseguir el adecuado funcionamiento de los nuevos subsistemas urbanos regionales. Es lógico que sea así. Ahora bien, eso no impide formular la pregunta: ¿el mode- 
lo territorial predominante actual, de naturaleza autonómica centralizada, es el más adecuado para lograr una optimización de los recursos y responde plenamente a las realidades regionales?; ¿acaso no se ha reproducido casi miméticamente en cada CA el esquema centralizado tradicional, tan denostado, de la España centralista, trasladándolo a las nuevas entidades territoriales?; ¿no se intenta hacer de cada capital autonómica el centro indiscutible, a veces poco lógico, de la mayoría de las funciones, de casi todos los bienes y servicios de rango elevado (sobre todo los de naturaleza pública), de las correspondientes entidades autonómicas?. Extraña que esto último se advierte en algunas que ni siquiera contabilizan los umbrales de población mínimos y adecuados; y todo ello se hace en detrimento de otros centros urbanos más dinámicos. Considero que, en buena medida, esa dinámica ha ido imponiéndose de forma solapada y bajo la defensa indiscutible de la nueva realidad autonómica.

A veces se tiene la sensación de que el anterior centralismo «madrileño» se ha sustituido por nuevos «centralismos de las capitales autonómicas». En las siete CC.AA. uniprovinciales el resultado es menos gravoso, por razones obvias; se refuerza el organigrama provincial con el nuevo autonómico; no sucede lo propio en las restantes. En ellas se ha superpuesto la nueva organización administrativa autonómica a las provinciales existentes. Tal proceso, a menudo, origina duplicidad y repetición de funciones; mayores costes operativos y escasas ventajas para los ciudadanos. Conviene recordar que se hace referencia, en especial, a todos aquellos aspectos dependientes de los poderes públicos, en este caso autonómicos; los cuales, como se ha indicado, constituyen la mayor proporción de todos. Eso puede representar un cierto despilfarro de recursos públicos; tal ocurre cuando no se ha sido capaz de trasvasar servicios ni funciones desde las capitales provinciales (acaso menos necesarios ahora), a las nuevas sedes capitalinas autonómicas. Por consiguiente, en todas ellas, se han superpuesto las nuevas delegaciones autonómicas regionales a las previas. Su perjuicio no implica sólo costes económicos, también representa dificultades para una mejor agilidad en la prestación de servicios. Cada vez es más necesario considerar que los recursos son escasos, y el ciudadano quien todo lo sufraga con sus impuestos; por consiguiente, tiene derecho a exigir de los administradores la mayor racionalidad y eficacia.

Es cierto que el nivel de presencia de los poderes públicos (Estado y Ayuntamientos) era débil en España en los años setenta. Un Estado social, como señala nuestra Constitución, precisa incrementar sus prestaciones; para ello el número de servidores públicos tiene que crecer. Así ha sucedido. Pero, ¿era necesario un incremento tan fuerte?, ¿ha aumentado de la misma manera su eficacia y productividad? Son preguntas que quedan en el aire. Lo curioso es que son cuestiones «tabú» que nadie formula siquiera. Se ha creado una opinión generalizada de que todo lo «autonómico» es bueno y útil por excelencia, «per se»; frente a lo Estatal, que lo es menos, por no decir que malo o negativo. Opinión interesada, defendida por las nuevas «oligarquías de poder regionales», y, con más vehemencia aún, desde los círculos regionalistas y nacionalistas, que ven en ello un campo futuro a través del cual conseguir «más influencia y poder».

También resulta interesante comprobar con qué fuerza, pasión e intensidad los poderes autonómicos plantean frente al Estado sus exigencias de poder. Lo acompañan de los más plurales argumentos: legales, e incluso «morales y éticos»; siempre diciendo que desean alcanzar al máximo la proximidad con el ciudadano. Por el contrario, resulta curioso constatar lo menos dispuestos que están para favorecer la descentralización hacia otros entes más pequeños: comarcales o locales. Además, la realidad muestra frecuentes ejemplos en varios Estados donde el sistema político funciona correctamente de esa manera. Aquí, parece que el nivel autonómico es el único existente; el destinatario absoluto de cualquier proceso de descentralización del Estado. A él todo le corresponde; cuanto más reciba y 
disponga mejor; mientras que de él nada debe partir hacia los demás entes territoriales menores; eso se considera una acción contraria a lo autonómico.

Hace años, tras sus inicios, García de Enterría alertó de los riesgos y males que se cernían, precisaba: «las ingenuidades, los dispendios, los personalismos, los clientelismos, las disfuncionalidades, las corrupciones incluso, la tendencia a rellenar organigramas abstractos, todo eso y mucho más, propio de la infancia de cualquier organización, prolifera notoriamente en el ámbito autonómico, con más viveza que en la Administración del Estado... y que es aún, en una cierta medida al menos, la organización del desgobierno» (1987, pp. 1320). Transcurridos varios lustros, en numerosos casos la madurez y el realismo se ha ido imponiendo. Pero, no son pocos los ejemplos que dan la razón, sobradamente, a lo indicado. Por suerte la grandeza de toda democracia radica en la capacidad de elegir de los ciudadanos entre diferentes opciones; pero todos sabemos que ese principio teórico queda disminuido a través de numerosas vías. Desgraciadamente ejemplos de ello se confirman a menudo; temo que no son infrecuentes tampoco en España.

Nunca se debe olvidar que el buen funcionamiento del sector público es una garantía de mejora de nuestra calidad de vida. Sobre el tema autonómico se tiene la impresión que se actúa con demasiada indulgencia de manera generalizada, exigiéndole poco, diculpándole mucho, desviándole responsabilidades; cuando en realidad ya es, en numerosos apartados, el gestor fundamental de la vida pública en España. En cierta medida se percibe que sobre ese asunto existe una especie de «consenso generalizado» de disimulo, en el que participan todas las fuerzas políticas y sociales; en especial, porque todas son, o aspiran a ser, copartícipes de su gestión y de sus beneficios.

Las anteriores reflexiones no deben considerase como una crítica a ese nivel de gobierno del sistema; es tan legítimo y democrático como otro centralizado y «jacobino». Pienso que para lograr una adecuada y profunda vertebración de España (en el sentido que apuntaba Ortega y Gasset, 1933) puede ser más eficaz que otro. Lo importante es que funcione con eficacia y racionalidad. De lo contrario, se puede llegar a una «solidaridad de los particularismos», donde la endogamia se generalice y conduzca a un localismo ramplón (como también nos prevenía Ortega, 1931), y se convierta en favorecedor de la ineficacia y el despilfarro.

\section{Algunas apostillas finales}

La Historia de Europa muestra una tremenda amalgama y sucesión de pueblos que, al paso de los siglos, buscan su acomodo en el angosto territorio común, siendo constantes las tensiones, luchas y enfrentamientos de unos con otros, hasta tiempos recientes (Cfr. Brubaker, 1996; Caplan; Feffer, 1996). Sólo partiendo de ese pasado se entiende la realidad presente. En la Península Ibérica tras el dominio romano, y la posterior presencia islámica, a lo largo de la Edad Media se formaron una serie de núcleos de resistencia que en su avance hacia el sur originaron los conocidos reinos medievales. Quizás, una peculiaridad de España es que durante el periodo en que tienen lugar las fuertes transformaciones tecnológicas e industriales, en especial el siglo XIX, la debilidad del Estado impidió, como sucedió en otros países de nuestro entorno, llevar a cabo una tarea de mayor presencia, organización y homogeneidad del conjunto nacional, lo cual permitió la pervivencia de variedades territoriales, que, en algunos casos, se remontaban a la Edad Media, permaneciendo su herencia (Cfr. Linz, 1981; Hobsbawn, 1995). La accidentada topografía facilitó la compartimentación territorial. No en balde resulta curioso comprobar la semejanza en muchos aspectos de la actual organización espacial autonómica con la dimensión y morfología de los antiguos reinos medievales. La racional y bien trabada división provincial de 1833 (Calero, 1987), si 
bien se ha consolidado con vigor, no resulta suficiente para cubrir las peculiaridades territoriales españolas. Esa realidad no era desconocida por cualquier persona formada que se moviese fuera de la esfera oficial del franquismo y su doctrina imperante. Así, J. Marías, escribió: «la geografía no tiene que ver demasiado con la geometría; tiene mucho más que ver con la historia. La variedad de España es multiplicidad; y esto puede ser riqueza, fertilidad, esplendor, si esas facetas se van sumando y conservando; si se evitan las dos tentaciones capitales: la inerte pasión por la homogeneidad, la incoherente fragmentación; la mirada con que contemplemos a España no puede ser ni una apisonadora ni un ojo de mosca tallado en mil facetas inconexas... (1972, p. 82).

Acaso, todo eso explica que nuestros políticos, de forma realista y acertada, recogieron en el texto Constitucional de 1978 el modelo territorial autonómico que se analiza. Dada su trascendencia, sobre ello se ha escrito mucho y desde muy diferentes perspectivas. No es ésta ni la ocasión ni el momento de entrar en tales cuestiones. Además, resulta una ucronía pensar en cómo serían las cosas si se hubiesen desarrollado de otra forma. La realidad es que, en poco tiempo se ha puesto en funcionamiento un sistema político muy descentralizado en su organización territorial; tanto o más, que la existente en otros Estados Federales; realidad objetiva, palpable e indiscutible. La cuestión central es que tal modelo, acaso sobrepasaba las aspiraciones comunes de la población residente en la mayoría de las hoy CC.AA. españolas. Lo que para unos ha sido un paso por demás, no se ve así por otros; que, en parte, desde los grupos políticos que defienden esos postulados, hacen de la diferencia - su diferencia - su peculiaridad y su singularidad, frente al resto, motivos de agravio permanente. El sistema fue aceptado en principio de buen grado por todos; pero tras unos años, necesarios para asimilar lo transferido y contemplado en el texto constitucional, aquellos que propugnan mayor amplitud autonómica, desean una ampliación de su capacidad de autogobierno; y manifiestan su descontento (Fusi, 1992). Ello puede originar, en tanto que efecto demostración, otros seguidismos. La complejidad de estas cuestiones es enorme, porque, a nadie se oculta, que se entrecruzan elementos sociológicos y sociales, en su sentido más amplio, económicos, de naturaleza política (actual, coyuntural y a más largo plazo) $\mathrm{y}$, todo ello, con una vertiente territorial, que es nuestro centro de atención preferente. Por consiguiente, no es posible, ni tendría sentido, intentar siquiera un bosquejo de análisis de esa compleja realidad, sólo me permito aportar algunas apostillas sobre ciertos aspectos.

El último cuarto de siglo ha supuesto para España un periodo de profunda modernización, de gran crecimiento económico, dentro de varias fases y subperiodos diferentes, que ha permitido aproximar nuestros niveles de riqueza al promedio Comunitario; además de integrarnos con fuerza en dicha Unión. También dentro de España se aprecia una cierta aproximación en los valores de riqueza por persona, entre las dispares CC.AA. Lo cual abre la esperanza de caminar hacia una cierta convergencia.

En el lado opuesto la dinámica territorial de localización de los efectivos humanos sigue mostrando una tendencia divergente. Los contrastes regionales se incrementan. Si ya se partía de apreciables diferencias demográficas, cada vez el peso poblacional de las CC.AA. es más contrastado. Con lo cual, su significación, en población, recursos económicos y productivos absolutos resulta más disímil.

Por otra parte, el afianzamiento de la nueva estructura del Estado es palpable, a la vez que el protagonismo de los nuevos entes territoriales, las CC.AA., se acrecienta de forma interesada. Con apoyos de muy dispar índole, se han ido configurando como sujetos casi naturales; si bien conviene recordar su propia naturaleza de entes políticos y, no hay nada natural en las sociedades políticas, pues «todo lo que al hombre se refiere es histórico y, lo histórico es inexorablemente cambio, vicisitudes y alternativa mudanza» (Ortega y Gasset, J., 1973, p. 23). Por ello, junto a esa consideración favorable e indulgente de los entes autonómicos, no viene 
de más ser exigentes con los mismos — gobiernos y demás responsables - , entre otras cuestiones, para alcanzar una mejor gestión de los cuantiosos recursos que administran, a la vez que se precisa una mayor coordinación con los otros niveles político-administrativos: el Estado y las Administraciones Locales.

Pero, junto a los indiscutibles logros que ha conllevado el sistema territorial autonómico, son numerosos los indicadores que muestran que tal sistema no se encuentra cerrado y no satisface, de manera suficiente, a ciertas CC.AA. Tras un cuarto de siglo de andadura de ese modelo territorial, cuando ya toda una generación de españoles han nacido y vivido dentro del mismo, se constata con pena que los recelos y las rivalidades regionales se han avivado en España. A la vez que se observa un cierto «anarquismo centrífugo». También se constata una enorme topolatría y excesiva exaltación del terruño, que desemboca, incluso, en una especie de «linaje territorial» anacrónico y poco realista; donde ciertas CC.AA. se autoproclaman con mayor nivel y mérito que las demás; cuando, si de algo anda sobrada toda la «vieja Europa» es de pasados históricos esplendorosos, sepultados al paso del tiempo. La cuestión se hace problema «cuando a la gente le preocupa ante todo su nacionalidad o identidad étnica particular y empieza a examinar cada pronunciamiento político y cada acontecimiento local en busca de implicaciones para dicha identidad» (Jackson, 2001, p. 130). Corresponde a los partidos políticos, en especial a los de ámbito nacional, evitar entrar en tales cuestiones de manera partidista; sin falsos complejos; y, menos aún, utilizarlas, apoyándose en ellas, en su normal confrontación ideológica. Su visión de Estado debe anteponerse siempre. También, quienes creemos en el proyecto común de una España democrática estamos obligados a trabajar, generando ilusión y defendiendo nuestra Constitución. Sin caer en el riesgo de anteponer a esos nacionalismos regionales otro nacionalismo español; pues como decía A. Camus, amo demasiado a mi país como para ser nacionalista.

Acaso para entender mejor cuanto sucede en nuestras inmediaciones puede ayudarnos ampliar la escala de la mirada. Se acaba de aprobar una Constitución Europea (que agrupa a 25 Estados y cuenta con unos 450 millones de habitantes), a pesar de grandes dificultades la construcción Comunitaria avanza sin parar. La Península Ibérica, y por ende España, ocupa un espacio marginal, alejado de sus nodos centrales, en cierta situación de desenclave. Sólo la unión entre todos puede ayudarnos a encarar mejor los retos que el futuro presentará. Puede ser difícil encontrar fórmulas de consenso para alcanzar un modelo territorial aceptado por todos. Pero es el único horizonte posible. La propia integración del conjunto español y el bienestar de los ciudadanos lo demanda, a lo cual contribuyen con fuerza los logros alcanzados durante los últimos lustros. Es fácilmente constatable la cómoda accesibilidad, a través de los diversos medios de transporte, que permiten a cualquier español desplazarse en pocas horas de un extremo a otro de su territorio. Al hacerlo, todos podemos comprobar la realidad existente; que, si bien muestra ciertas diferencias de matiz, o paisajísticas, las cuales confirman nuestra variedad y pluralidad, fruto del mestizaje de tantos siglos unidos y de una convivencia tan prolongada y fecunda, no hay ningún fundamento para creer en una diferencia ni pureza territorial, consecuencia de un idealismo romántico falso e ignorante. Es, con mucho, más lo que nos une y asemeja, que lo que nos puede diferenciar. Por todo lo cual, estimo, que debemos estar satisfechos y orgullosos los españoles de lo que se ha conseguido en estos 25 primeros años de vigor de nuestra Constitución; pues gracias a ella el progreso y bienestar nos ha llevado a ser uno de los países con mayor calidad de vida del Planeta (Gaviria, 1996). Unas CC.AA. activas y dinámicas, dentro de un Estado, cada vez mejor vertebrado y armonioso, que garantice la solidaridad, dentro de un marco de libertad y de justicia, puede hacer posible proseguir con ese incremento y generalización del bienestar. Todo ello permitirá responder al reto que representa la ampliación de la Unión Europea, en un mundo tremendamente competitivo como el que vivimos. 


\section{Referencias bibliográficas:}

ALONSO FERNÁNDEZ, J. (1986): «La regionalización española actual». Teoría y práctica de la Geografía. Coord. A. García Ballesteros, Madrid, ed. Alhambra, pp. 88-96.

- (1990): La nueva situación regional. Madrid, ed. Síntesis, 166 pp.

BANCO DE BILBAO-VIZCAYA-ARGENTARIA (2000): La renta nacional de España y su distribución provincial, año 1995 y avances 1996-99. Bilbao, 546 pp. Consulta de varios años de la serie.

BANCO DE BILBAO-VIZCAYA-ARGENTARIA (2001): Informe Económico, 2000, Bilbao 220 pp. Consulta de varios años de la serie.

BENEYTO, J. (1980): Las Autonomías. El poder regional en España. Madrid, ed. Siglo XXI, $325 \mathrm{pp}$.

BODEGA FERNÁNDEZ, Mª . J.; CEBRIÁN DE MIGUEL, J.A. (1995): «Una lectura económica de algunas migraciones contemporáneas. El caso de España». Estudios Geográficos, Madrid, vol. LVI, n 221, pp. 665-694.

BOUDEVILLE, J. (1961): Les espaces économiques. Paris, P.U.F., 127 pp.

- (1966): Problems of regional economic planning. Ed. ing. Edinburgh at the University Press, $192 \mathrm{pp}$.

BRADSHAW, R.P.; ESTÉBANEZ ÁLVAREZ, J. (1985): «Región y regionalización». Paralelo $37^{\circ}, \mathrm{n}^{\circ} \mathrm{s}$ 7-8, Universidad de Granada, pp.97-113.

BREULLY, J. (1990): Nacionalismo y Estado. Barcelona, ed. esp. Pomares-Corredor.

BRUBAKER, R. (1996): Nationalism reframed. Nationhood and the National question in the New Europe. Cambridge, Cambridge University Press.

BURGUEÑO, J. (1996): Geografía política de la España Constitucional. La división Provincial. Madrid, Centro de Estudios Constitucionales, 433 pp.

CABRÉ, A. et al. (1985): «Cambio migratorio y reconversión territorial en España». Revista Española de Investigaciones Sociológicas, $\mathrm{n}^{\mathrm{O}} 32$, pp. 43-65.

CALERO AMOR, A.M ${ }^{\mathrm{a}}$. (1987): La división provincial de 1833. Bases y antecedentes. Madrid, Instituto de Estudios de Administración Local, 190 pp.

CAPLAN, R.; FEFFER, J. (1996): Europe's New Nationalism. States and Minorities in Conflict. Oxford, Oxford University Press.

CASELLA, A. (1996): «Large Countries, Small Countries and the Enlargement of trade Blocks». European Economic Review. Vol. 40, pp. 389-415.

CASTELLS, A. ( 2000): «Autonomía y solidaridad en el sistema de financiación autonómica». Papeles de Economía Española, nº 83, FIES, Madrid, pp. 37-59.

CLAVERO ARÉVALO, M. (1983): España desde el centralismo a las autonomías. Barcelona, ed. Planeta, $223 \mathrm{pp}$.

COLOMER, J.M. (1999): «La autocrisis del Estado de las Autonomías». Claves de Razón Práctica, Madrid, no 94, Julio-Agosto, pp. 18-21.

CORAGGIO, J.L. (1985): «Polarización, desarrollo e integración». Desarrollo polarizado y políticas regionales. Homenaje a J. Boudeville. México, ed. Fondo de Cultura Económica, pp. 49-68.

CORI, B. (1995): «Urban networks». Geo-Italy, vol. 2, Patron ed., Bologna, pp.13-20.

CORNA PELLEGRINI, G. (1995): «The study of urban networks». Geo-Italy, vol. 2 , Patron ed., Bologna, pp. 20-35.

CUADRADO ROURA, J.R. (1987): Los desequilibrios regionales y el Estado de las Autonomías. Barcelona, ed. Orbis, $141 \mathrm{pp}$.

- (dir.) (1998): Convergencia regional en España. Hechos, tendencias y perspectivas. Madrid. Fundación Argentaria, Visor. 
DEL CAMPO, S.; NAVARRO, M.; TEZANOS, J.F. (1977): La cuestión regional española. Madrid, ed. Cuadernos para el diálogo, $325 \mathrm{pp}$.

DICKINSON, R.E. (1961): Ciudad, región y regionalismo. Ed. esp. Barcelona, Omega, $385 \mathrm{pp}$.

DUMOLARD, P. (1975): Régions et régionalisation. Une approche systémique. L' Espace Géographique, vol. IV, nº 2, 93-111.

FLORISTAN SAMANES, A. (1988): España, país de contrastes geográficos naturales. Madrid, ed. Síntesis, 157 pp.

FREMONT, A. (1976): La région. Espace vécu. Paris, P.U.F., 223 pp.

FUENTES QUINTANA, E. (1988): «Tres decenios de la economía española en perspectiva». En España. Economía. Dir. J. L. García Delgado. Madrid, ed. Espasa Calpe, pp. 1-78.

FUSI AIZPURURA, J.P. (1992): «De las aspiraciones históricas al Estado de las Autonomías». Historia 16, n⿳0 200, pp. 24-31.

GÁMIR, L. (Dir.) (1999): La convergencia real de la economía española. Madrid, ed. Pricewaterhouse Coopers, 197 pp.

GARCÍA ÁlVAREZ, J. (2002): Provincias, regiones y Comunidades Autónomas. La formación del mapa político de España. Madrid, ed. Temas del Senado. 778 pp.

GARCÍA BARBANCHO, A. (1967): Las migraciones interiores españolas. Estudio cuantitativo desde 1900. Madrid, ed. Instituto de Desarrollo Económico.

- (1979): Disparidades regionales y ordenación del territorio. Barcelona, ed. Ariel, 269 pp.

GARCÍA BARBANCHO, A.; DELGADO CABEZA, M. (1988): Los movimientos migratorios interregionales en España desde 1960». Papeles de Economía Española, $\mathrm{n}^{\circ}$ 34, Madrid,pp. 240-266.

GARCÍA DE ENTERRÍA, E. (1984): «El futuro de las autonomías territoriales». España, un presente para el futuro. Madrid, vol. II, Instituto de Estudios Económicos, pp. 99-120.

- (1987): «Sobre el modelo autonómico español y sobre las actuales tendencias federalistas». Cuenta y Razón, $\mathrm{n}^{\circ}$ 30, pp. 13-20.

GAVIRIA, M. (1996): La séptima potencia. España en el mundo. Barcelona, Ediciones B, $435 \mathrm{pp}$.

GIDDENS, A. (2003): Un mundo desbocado. Ed. esp. Madrid, Taurus, 116 pp.

GOZÁLVEZ PÉREZ, V. (1995): «L'inmigration étrangère en Espagne (1985-94)». Revue Europenne des Migrations Internationales, vol. Vl, $\mathrm{n}^{\circ}$ 1, pp. 11-38.

HERBERT, D.T.; THOMAS, A.C. (1990): Cities in space: city as place. Londres, Davil Fulton Publishers, 340 pp.

HERRERO DE MIÑÓN, M. (2004): «El Estado integrado, ¿señor o miembro de la UE? Política exterior, $\mathrm{n}^{\circ}$ 100, Julio-Agosto, Madrid, pp. 127-136.

HIGUERAS ARNAL, A. (1980): «Los desequilibrios regionales en España». La Región y la Geografía Española, Valladolid, ed AGE, 127-142 pp.

HOBSBAWN, E. (1995): Naciones y nacionalismo desde 1870. Barcelona. Ed. esp. Crítica.

IGNATIEFF, M. (1999): El honor del guerrero. Guerra étnica y conciencia moderna. Madrid, Taurus.

JACKSON, G. (2001): Ciudadano Jackson, Barcelona, Martínez Roca, Eds., 314 pp.

JAÉN, M., MOLINA, a. (2001): «Efectos distributivos del gasto público en España». Papeles de Economía Española, no 88, pp. 198-215.

JIMÉNEZ BLANCO, J. (dir.) (1977): La conciencia regional en España. Madrid Centro de Investigaciones Sociológicas.

JOHNSON, N. (1990): El Estado de bienestar en transición. La teoría y la práctica del pluralismo del bienestar. Ed. es. Madrid, Ministerio de Trabajo y Seguridad Social, $286 \mathrm{pp}$. 
JUILLARD, E. (1962): «La région, essai de définition». Annales de Geographie, 71. Incluido este trabajo también en la publicación del Autor: La «Région». Contributions a une Géographie Générale des Espaces Réginaux». Ed. Ophrys, Paris, 1974, pp. 27-43.

- (1974): La Région. Contributions a une Géographie Générale des espaces Régionaux. Paris, ed. Ophrys, $230 \mathrm{pp}$.

LINZ, J.J. (1981): «La crísis de un Estado unitario, nacionalismos periféricos y regionalismos». La España de las autonomías. Madrid, ed. Espasa-Calpe, pp. 651-752.

LÓPEZ TRIGAL, L. (1985): «Límites, sedes y entidades territoriales en los Estatutos de Autonomía». Actas, X Reunión de Estudios Regionales, vol. II, León, pp. 755-764.

MARÍAS, J. (1972): Nuestra Andalucía y consideración de Cataluña. Madrid, ed. de la Revista de Occidente. Col. El Alción, 173 pp.

- (1987): «La tentación federal». Cuenta y Razón, nº 30, pp. 7-12.

MARSHALL, J.U. (1989): The structure of urban systems. Toronto, Universityy of Toronto Press, $394 \mathrm{pp}$.

MARTÍN RODRÍGUEZ, M. (1990): «Evolución de las disparidades regionales: una perspectiva histórica». En García Delgado, J. (dir.), España. Economía, Madrid, Espasa-Calpe, pp. 703-743.

MAS, M.; MAUDOS, J.; PÉREZ,; URIEL, E. (1996): «Infrastrucures and convergence in Spanish regions». Regional Studies, vol. 30, nº 7, pp. 641-49

MELLA MÁRQUEZ, J.M‥ (coordinador) (1998): Economía y política regional en España ante la Europa del Siglo XXI. Madrid, ed. Akal, 703 pp.

MUÑOZ PÉREZ, F.; IZQUIERDO ESCRIBANO, A. (1989): «L'Espagne, pays d'inmigration». Population, $\mathrm{n}^{\circ}$ 2, pp. 257-289.

OLIVER, J.; RAMOS, X.; RAYMOND, J.L. (2002): «La desigualdad en la distribución de la renta en la Unión Europea a mediados los noventa». Papeles de Economía Españala, $\mathrm{n}^{\circ}$ 91, pp. 129-150

ORTEGA Y GASSET, J. (1931): La redención de las provincias. Madrid, Ed. Revista de Occidente, consulta de la edición de 1973, 300 pp.

- (1933): La España invertebrada. Madrid, ed. Revista de Occidente, con. la $17^{\text {a }}$ ed. de $1975,163 \mathrm{pp}$.

- (1973): Vives-Goethe. Madrid, ed. Revista de Occidente. Col. El Arquero, 230 pp.

POPPER, K.R. (1985): La sociedad abierta y sus enemigos. Ed. esp., Barcelona, Orbis, 2 vols.

PUYOL ANTOLIN, R. (1979): Emigración y desigualdades regionales en España, Madrid, Emesa, 215 pp.

- (editor). (1997): Dinámica de la población en España. Cambios demográficos en el último cuarto del siglo XX. Madrid, ed. Síntesis, 399 pp.

RAMÓN, $M^{\mathrm{a}}$.D.; GARCÍA SOLANES, J. (2002): Convergencia real de las regiones españolas. El impacto de los fondos estructurales». Papeles de Economía Española, $\mathrm{n}^{\circ}$ 93, pp. 51-63.

RODRÍGUEZ OSUNA, J. (1978): Población y desarrollo en España. Madrid, Planeta, Cupsa Editorial, 178 pp.

- (1985): Población y territorio de España. Siglos XIX y XX. Madrid, ed. Espasa-Calpe, $219 \mathrm{pp}$.

SÁNCHEZ AGESTA, L. (1980): El sistema político de la Constitución Española de 1978. Ensayo de un sistema. Madrid, Editora Nacional, $471 \mathrm{pp}$

SERRANO MARTÍNEZ, J.M ${ }^{\mathrm{a}}$. (1987 ): «Los saldos migratorios interiores en España entre 1973 y 1982. ¿Situación coyuntural o cambio de tendencia?». Información Comercial Española, Ministerio de Economía y Hacienda, Madrid, nº 647, pp. 71-92. 
- (1989): «L'Espagne: Les disparités régionales dans la densité de population en 1986. ¿Fin d'un processus d'augmentation des désequilibres internes». Acta Geographica, Societé de Géographie, Paris, n 79 pp. 20-38.

SERRANO MARTÍNEZ, J.M'.; KAUFMANN, R. (1993): Die regionale Gliederung Spaniens: Schwierigkeiten und Wiederprüche der neuen Territorialstruktur. Giessen, Zentrum für Regionale Entwicklungsforchung des Justus Liebig Universität von Giessen, $140 \mathrm{pp}$.

- $(1994, a):$ "The creations of regions in Spain and its consequences of urban system and its hierarchy». Bulletin de la Societé Belge d'Etudes Geographiques, 1994-1, Univ. de Lovaina, pp. 31-45.

SERRANO MARTÍNEZ, J.Mª ; KING, R. (1994, b): Urban systems and regional organization in Spain. University of Sussex. Brigthon, $61 \mathrm{pp}$.

- (1995): «Changes in the interregional migratory pattern in Spain. Causes and reflections». Bulletin de la Societé Belge d'Etudes Géographiques. Univ. de Lovaina, ${ }^{\circ}{ }^{1}$, pp. 7-26

SERRANO MARTÍNEZ, J.Ma .; CALMÉS, R. (1998): L'Espagne. Du sous-développement au développement. L'Harmattan, Paris, $304 \mathrm{pp}$.

- (2003): España en el nuevo milenio. Realidad territorial y retos pendientes, Murcia, Servicio de Publicaciones, Universidad de Murcia, 683 pp.

SERRANO; SCHLIEPHAKE, K. (2004): «Spaniens modernes Strassennetz (Autobahnen und Schnellstrassen) und seine Bedeutung für die räumliche Entwicklung». Wurzburger Geographische Manuskripte. Heft 67; pp. 111-127; KONRAD SCHLIEPHAKE und TILMAN, A. SCHENK: Verkehrsgeographie, Mobilität, Logistik und Infrastruktur: Wurzburg.

SETON-WATSON, H. (1977): Nation and States. An Inquiry into the origin of Nations and the politics of Nationalism. Londres, Methuen.

URIEL, E. (2002): «La Administración Pública Central y la redistribución territorial de la renta». Papeles de Economía Española, no 93, pp. 148-167.

VILLAVERDE CASTRO, J.; PÉREZ GONZÁLEZ, P. (1996): «Los ejes de crecimiento de la economía española». Papeles de Economía Española, nº 67, Madrid, pp.63- 80.

VILLAVERDE CASTRO, J. (2001): «La distribución espacial de la renta en España». Papeles de Economía Española, no ${ }^{\circ 8}$, pp. 166-180.

UTRILLA DE LA HOZ, A. (2000): «Consolidación fiscal y endeudamiento regional, evolución y perspectivas». Papeles de Economía Española, n 83, FIES, Madrid, pp.168183. 